\title{
Key stimuli and the recognition of the physical environment by the paradise fish Macropodus opercularis
}

\author{
V. CSÁNYI and F. LOVÁSZ \\ L. Eötvös University of Budapest, Hungary
}

\begin{abstract}
Recognition of features of the physical environment by the paradise fish was examined in the course of passive avoidance conditioning, in the presence of a key-stimulus-carrier dummy. During conditioning, the fish were placed into one of two differently arranged shuttle-tanks according to a random schedule. If a fish entered the dark compartment of one of the tanks it was punished by shock or, for some groups, confronted by a predator-like dummy; the other tank was safe and without the dummy. It was found that in the presence of the key stimulus carrier, associative learning was concentrated on the stimulus carrier, and that the less salient features of the physical environment were not associated with the punishment.
\end{abstract}

Many prey animals have been found to emit speciesspecific passive and active avoidance behavior patterns in the presence of living or model predators (Gallup, Nash, \& Ellison, 1971; Coss, 1979; Hinde, 1954; Kruuk, 1964; Owings \& Cross, 1977). There is also some evidence that learning may improve predator avoidance behavior (Curio, Ernst, \& Vieth, 1978; Kruuk, 1976; Schleidt, Shalter, \& Carawan, 1983).

Processes of predator recognition by the paradise fish have been studied before (Csányi, 1985a, 1985b, 1986). It has been found that the appearance of a living fish of another species in the environment elicits exploratory behavior in the paradise fish and that the outcome of the first encounter strongly influences subsequent meetings. Encounter with an attacking predator results in "avoidance behavior' in subsequent meetings independently of the actual behavior of the predator. In experiments using a passive avoidance conditioning paradigm with various dummies or living goldfish as signal stimuli, the role of eyespot pattern as a specific key stimulus was discovered (Csányi, 1985b). It was found that a low-intensity shock, while clearly uncomfortable, elicited exploratory behavior in the paradise fish, although observable learning did not occur. However, if the paradise fish was shocked in the presence of living goldfish or very simple dummies with two horizontally arranged eye-like spots, avoidance learning was clearly detectable.

In a recent study (Csányi \& Gervai, 1986), a considerable genetic variation in the response to passive darkavoidance learning under the effect of a key stimulus was found among inbred paradise fish strains, with the implication that a within-species variation of the interaction of

This work was supported by a grant from the Hungarian Academy of Sciences (498/85). The authors are very grateful to Judit Gervai for her help in the statistical analysis. The authors' mailing address is Department of Behavior Genetics, L. Eötvös University of Budapest, Jávorka S.u.14, Göd H-2131, Hungary. the species-specific defense reaction (Bolles, 1970) might depend on a complex interaction of innate and environmental factors.

In the present experiment, the recognition of features of the physical environment in the course of passive avoidance conditioning in the presence of a key-stimulus carrier dummy was examined.

\section{METHOD}

\section{Subjects}

$F_{1}$ hybrid adult females of two inbred strains of Macropodus opercularis, designated as strains $\mathbf{S}$ and $\mathrm{U}$, were used as subjects. The fish were bred in our laboratory and were 120 to 180 days old at the time of the experiment. During the experiment, they were housed in small, 6-liter, individual aquaria. These aquaria were well filtered, their temperature $\left(28^{\circ} \mathrm{C}\right)$ was held constant, and each tank contained a piece of water plant (Hygrophila polysperma). The animals were fed daily on Tubifex worms.

\section{Apparatus}

The shuttle-tanks used and the details of monitoring shuttling activity were the same as those used and described earlier (Csányi, 1985b). Two differently arranged shuttle-tanks were used in this experiment. Both compartments of tank A were empty; in tank B, some water plants, pebbles, and various pieces of small rocks were arranged on both the light and dark sides to make it as visually different as possible from tank $A$. The locations of the two tanks in the experimental room were also different.

The dummy used in this experiment was made from the head of a plastic toy fish with the eyes replaced by two small red lamps.

\section{Procedure}

Thirty fish were divided into three equal-sized groups. Fortyeight hours prior to training, all fish were placed into individual aquaria. During training sessions, once a day, each fish was placed into the transparent compartment of either $\operatorname{tank} A$ or $\operatorname{tank} B$, assigned according to a random schedule generated by a computer, where it received various treatments. Fifteen minutes later, the fish was removed from the apparatus and returned to its home tank. All training experiments were carried out between 9:00 a.m. and 4:00 p.m. The first 12 trials were allowed for habituation, with 
neither electric shock applied nor dummy present; each fish visited each shuttle tank at least five times. In shock treatment, the fish got a train of electric shocks if it entered the dark compartment (a 20-msec train of 500-Hz, ac, 75-mA shock every fifth second, with the first train given immediately after the fish's entrance). All shock treatments were applied in shuttle-tank A.

In Conditioning Trials 1-7, the treatments of the groups were as follows: (1) Group DS-After the habituation trials, the dummy was placed into the dark compartment of shuttle-tank A and shocks were applied. (2) Group S-After the habituation trials, shocks were applied in shuttle-tank A. (3) Group C served as a control, with neither shock nor dummy applied.

For Group DS, two further conditioning trials (8-9) were performed in tank A. On Trial 8, the dummy was removed and shocks were not applied. On Trial 9, the dummy was placed back into the dark compartment but shocks were omitted again.

In the statistical analysis, the entrance latency of those fish that remained in the transparent compartment during the whole trial were assigned as $900 \mathrm{sec}$ : before calculating the appropriate statistics, all raw data were logarithmically transformed.

\section{RESULTS}

For appropriate comparisons, latencies were separated within each group according to A or B shuttle-tank assignments and the respective group means for each trial were calculated (Figure 1). A three-way analysis of variance was performed with groups (DS vs. S vs. C) as a between-groups factor and tanks (A vs. B) nested within the groups variable and trials as repeated measures. The differences were found to be significant $[F(2,54)=119.9$, $p<.00001, F(1,54)=114.65, p<.00001$, and $F(6,324)=36.99, p<.000001$, for treatment, tanks, and trials, respectively]. The treatment $\times$ box $[F(2,54)$ $=48.0, p<.00001]$, trial $\times$ treatment $[F(12,324)=$
9.67, $p<.000001]$, trial $\times \operatorname{tank}[F(6,324)=10.48$, $p<.000001]$, and trial $\times$ treatment $\times$ tank $[F(12,324)$ $=4.3, p<.00001]$ interactions were also found to be significant.

Some pairwise comparisons for Trial 7 were calculated. $F$ values for treatments are shown in Table 1 . Treatment with shock or dummy + shock in shuttle-tank A raised latency significantly, but the fish treated with shock alone also showed high latencies in the "safe," B tank. Fish shocked in the presence of the dummy did not show an increased latency in tank B.

For Group DS, when the dummy and shock were removed from tank $A$ on Trial 8, the fish readily entered into the dark compartment, so this group's average latency on Trial 8 differed significantly from that on the preceding conditioning trial, Trial 7 , which was performed in the presence of the dummy $[F(1,18)=33.5$, $p<.001]$. The return of the dummy on Trial 9 caused a large increase in latency [Figure $1 ; F(1,18)=20.6$, $p<.001]$.

\section{DISCUSSION}

It had previously been found that paradise fish could be conditioned to avoid the dark chamber of a shuttletank by using either high electric shock alone or a weak shock combined with the simultaneous presentation of a key-stimulus-carrier fish dummy as punishment (Csányi, 1985b). In the present experiment, we used two differently arranged shuttle-tanks to study the ability of the paradise fish to recognize components of the physical environment, including a key-stimulus-carrier dummy. Presentation of the dummy and high-shock treatment al-

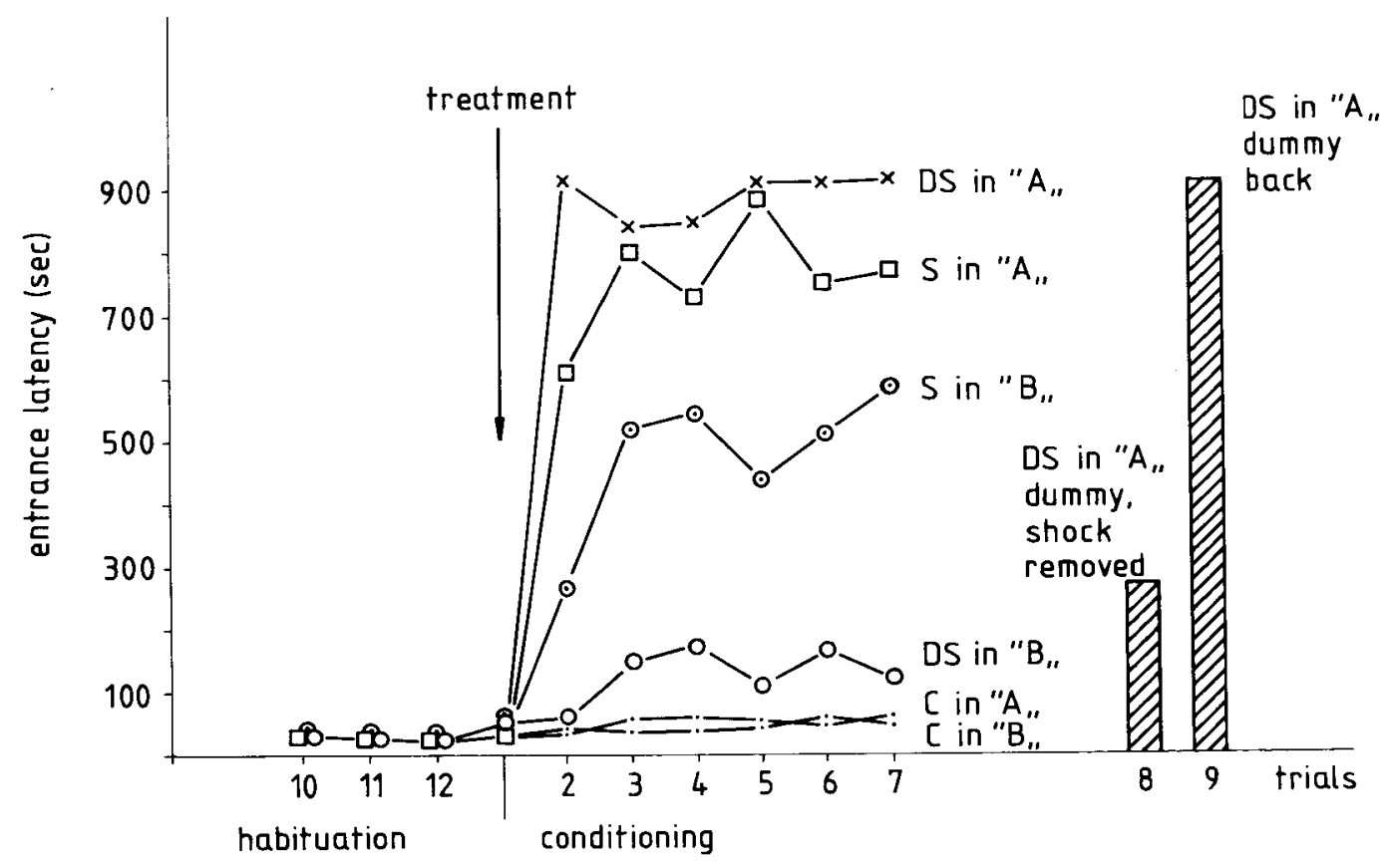

Figure 1. Effect of shock treatments as shown in the increase in latency of the paradise fish to enter the second compartment of the shuttle-tank. Groups are marked on the figure. 
Table 1

\begin{tabular}{|c|c|c|c|c|c|c|}
\hline \multicolumn{7}{|r|}{7} \\
\hline$F(2,18)=$ & DS in " $A "$ & $S$ in " $A$ " & $S$ in " $B$ "' & $D S$ in " $B$ " & $C$ in " $A$ " & $C$ in " $B$ " \\
\hline DS in " $A$ " & - & $\begin{array}{l}1.58 \\
\text { n.s. }\end{array}$ & - & $\begin{array}{c}79.2 \\
p<.0001\end{array}$ & $\begin{array}{c}442.3 \\
<.0001\end{array}$ & \\
\hline$S$ in " $A$ " & & - & $p \stackrel{5.1}{<.05}$ & - & $\begin{array}{c}126.3 \\
p<.0001\end{array}$ & \\
\hline$S$ in " $B$ " & & & - & $\begin{array}{l}20.1 \\
p<.001\end{array}$ & - & $\begin{array}{c}\quad 63.6 \\
<. .0001\end{array}$ \\
\hline DS in " $B$ " & & & & - & - & $\begin{array}{l}1.55 \\
\text { n.s. }\end{array}$ \\
\hline$C$ in " $A$ " & & & & & - & $\begin{array}{l}2.36 \\
\text { n.s. }\end{array}$ \\
\hline
\end{tabular}

ways occurred in one of the shuttle-tanks, and the results show clearly that either high shock alone or shock paired with the presentation of the dummy elevates latency significantly (Figure 1). Fish punished by high-intensity shock alone showed a large "transfer" effect; that is, their latency to move into the safe apparatus also increased significantly. The fish shocked with the same high intensity but in the presence of the dummy showed no significant transfer in the safe compartment.

One of the possible conclusions of this observation is that in the presence of key stimuli, associative learning is concentrated on the key stimulus carrier and the less salient features of the physical environment are not associated with the punishment. This conclusion was supported by observations made when the dummy was removed.

Another conclusion is that fish treated with painful highintensity shocks alone, in the absence of a key stimulus carrier, tend to "generalize" this experience and to show a "transfer" of avoidance behavior to the different, "safe" apparatus too.

The results can also be explained in the framework of the traditional two-factor avoidance learning theory of Mowrer (1947), which acknowledges the contribution to avoidance learning both of CS fear and of context fear. The presence of the dummy in this experiment can be regarded as a salient, very effective specific CS which overshadowed (Rescorla, 1968; Wagner, 1969) the other weaker, contextual stimuli of the apparatus.

The question of what role, if any, the features of the safe environment play in this transfer remains open. Are there some common visual cues in the two shuttle-boxes which serve as an organizational device in the process of association? Or do the paradise fish simply lose their motivation for exploration? Whatever the answer to these questions, there is one conclusion that seems to be strongly supported: key stimuli play a major role in the organization of memory for the paradise fish.

\section{REFERENCES}

Bolles, R. C. (1970). Species-specific defense reactions and avoidance learning. Psychological Review, 77, 32-48.

Coss, R. G. (1979). Delayed plasticity of an instinct: Recognition and avoidance of two facing eyes by the jewel fish. Developmental Psychobiology, 12, 335-345.

Cś́NYI, V. (1985a), Ethological analysis of predator avoidance by the paradise fish Macropodus opercularis: I. Predator recognition. Behaviour, 92, 227-240.

CSÁNYI, V. (1985b). Ethological analysis of predator avoidance by the paradise fish Macropodus opercularis: II. Key stimuli in learning. Animal Learning \& Behavior, 14, 101-109.

CSÁNYI, V. (1986). How is the brain modelling the environment? A case study on the paradise fish. In G. Montalenti \& G. Tecce (Eds.), Variability and behavioral evolution. Proceedings, Accademia Nazionale Dei Lincei, Roma 1983. (Quaderno No. 259)

CsáNYI, V., \& GervaI, J. (1986). Behavior-genetic analysis of the paradise fish (Macropodus opercularis): II. Passive avoidance learning in inbred strains. Behavior Genetics, 16, 553-557.

CURo, E. K., ERNST, K., \& VIETH, W. (1978). The adaptive significance of avia mobbing: II. Cultural transmission of enemy recognition in blackbirds: Effectiveness and some constraints. Zeitschrifi für Tierpsychologie, 48, 184-202.

Gallup, G. P., Nash, R. F., \& Ellison, A. L. (1971). Tonic immobility as a reaction to predation: Artificial eyes as a fear stimulation for chicks. Psychonomic Science, 23, 79-80.

Hinde, R. A. (1954). Factors governing the changes in strength of a partially inborn response, as shown by the mobbing behaviour of the chaffinch Fringilla coelebs: I. The nature of the response and the examination of its course. Proceedings of the Royal Society $B, 142$, 306-331

KruUk, H. (1964). Predators and antipredator behavior of the blackheaded gull Larus ridibundus. Behaviour, 11(Suppl.), 129 pp.

KRUUK, H. (1976). The biological function of gull's attraction towards predators. Animal Behavior, 24, 146-153.

MoWrer, O. H. (1947). On the dual nature of learning: A reinterpretation of "conditioning" and "problem solving." Harvard Educational Review, 17, 102-148.

Owings, D. H., \& Cross, R. G. (1977). Snake mobbing by California ground squirrels: Adaptive variation and ontogeny. Behaviour, 62, 50-69.

Rescorla, R. A. (1968). Probability of shock in the presence and absence of CS in fear conditioning. Journal of Comparative \& Physiological Psychology, 66, 1-5.

Schleidt, W. M., Shalter, M. D., * Carawan, T. C. (1983). The effect of spatial context on habituation to a predation model. Zeitschrift fur Tierpsychologie, 61, 67-70.

WAGNER, A. R. (1969). Stimulus selection and a modified continuity theory. In G. H. Bower \& J. T. Spence (Eds.), The psychology of learning and motivation (Vol. 3, pp. 143). New York: Academic Press.

(Manuscript received May 12, 1986 revision accepted for publication January 16, 1987.) 